\title{
Effect of Irrigation Water Source on Secondary Metabolites in Salix acmophylla and Their Potential to Impair Exsheathment of Gastro-Intestinal Nematodes
}

\author{
Awwad S ${ }^{1,2}$, Markovics A ${ }^{3}$, Halahlih F1, Yazbak \\ $A^{1}$, Haj-Zaroubi $M^{1,4}$, Muklada $H^{5}$, Klein J $D^{5}$ and \\ Azaizeh $\mathbf{H}^{1,2,4 *}$ \\ 'Institute of Applied Research, The Galilee Society, P.O. \\ Box 437, Shefa-Amr 20200, Israel \\ ${ }^{2}$ Tel Hai College, Department of Environmental Sciences, \\ Upper Galilee 12208, Israel \\ ${ }^{3}$ Department of Parasitology, Kimron Veterinary \\ Institute, P O. Box 12, Bet Dagan, 50250, Israel \\ ${ }^{4}$ Department of Natural Resources \& Environmental \\ Management, Faculty of Management, University of \\ Haifa, 199 Aba Khoushy Ave., Mount Carmel, Haifa, \\ Israel \\ ${ }^{5}$ Department of Natural Resources, Institute of Plant \\ Sciences, Agricultural Research Organization, Volcani \\ Center, 68 Hamakabim Rd, Rishon Le Ziyyon, Israel \\ *Corresponding author: Hassan Azaizeh, Institute of \\ Applied Research, Galilee Society, P.O. Box 437, Shefa- \\ Amr 20200, Israel
}

Received: April 09, 2021; Accepted: April 28, 2021; Published: May 05, 2021

\begin{abstract}
Willows (Salix), which are found worldwide, have secondary metabolites that are valuable as dietary supplements for animal feed. The objectives of the current study were to test the effects of irrigation source on the production of secondary metabolites and their potential to inhibit nematode exsheathment. Three willow ecotypes (Kishon, Meah Shearim, and Golan) were irrigated with Fresh Tap Water (FW) or Treated Wastewater (TWW). TWW irrigation resulted in a doubling of biomass production compared with FW, probably due to the presence of more nutrients, particularly nitrogen. The type of irrigation water (TWW vs. FW) did not affect the quantity and quality of secondary metabolites, such as phenols, in all three willow ecotypes, although there was a difference in the chemical profile of glycoside phenols between willow ecotypes. Biomass and secondary metabolite production differed greatly between ecotypes, which was evident in the differing concentrations of phenols and flavonoids. These varying concentrations in turned affected the inhibition of the exsheathment of larval L3 nematodes. The ethanol extract of the Kishon ecotype consistently resulted in more than $90 \%$ exsheathment inhibition when tested on the L3 larval stage, whereas extracts from Meah Shearim and Golan resulted in lesser inhibition. A sub-fraction of the ethyl acetate fraction obtained from Kishon had maximum activity with more than $90 \%$ exsheathment inhibition.
\end{abstract}

Keywords: Effluents; Ethanol extracts; Larval exsheathment inhibition; Plant secondary metabolites; Willow ecotypes

\section{Abbreviations}

COD: Chemical Oxygen Demand; DM: Dry Matter; FW: Fresh Water; GIN: Gastrointestinal Nematode; HPLC: High Performance Liquid Chromatography; ICP: Inductively Coupled Plasma; LEIA: Larval Exsheathment Inhibition Assay; PBS: Phosphate Buffer Solution; TKN: Total Kjeldahl Nitrogen; TSS: Total Suspended Solids; TWW: Treated Wastewater

\section{Introduction}

The genus Salix (Family Salicaceae) is a widespread woody species in natural habitats, and is also cultivated in many countries worldwide. It has high rates of evapotranspiration, and high tolerance to saturation in soils that leads to oxygen shortage in the root zone [1]. The leaves and fine stems of willow (Salix spp.) are richer in nutritive values for grazing ruminants than low quality summer pasture $[1,2]$. In addition to nutritious forage, the trees provide nutraceutical compounds such as anthelminthic, antioxidants, and analgesic secondary metabolites [3,4]. Bioactive ingredients from plants can control parasitic nematodes in animals; however, the concentration of these bio-active compounds in anthelmintic plants can be both seasonal, and species-dependent $[5,6]$. The willow species S. acmophylla was successful medium-quality forage for dairy goats when irrigated with secondary-treated wastewater [7]. Specific secondary compounds such as phenolic and salicylic acid found in willow fodder may be of significant value in maintaining and improving the health and welfare of dairy goats. Short-term feeding of dairy goats with willow fodder had positive effects on somatic cell counts, and might promote anti-inflammatory effects and/or delay mammary involution [7].

Gastrointestinal Nematode (GIN) parasitism in grazing ruminants is a severe problem worldwide $[6,8,9]$. Over the past five decades, the control of these GIN parasites has been achieved mainly through intensive chemoprophylaxis, based on the repeated use of anthelmintic drugs [8]. However, the exclusive reliance on synthetic compounds is not sustainable. There is heightened consumer concern over potential residues in food products or in the environment from chemicals administered to farm animals. The worldwide spread of anthelmintic resistance within worm populations, and the occurrence in some regions of multi-resistant strains is of great concern [10]. Cattle herds with up to 79\% Ivermectin-resistant nematodes were reported in Mexico $[9,11,12]$. Resistance to all classes of anthelmintics was detected in $48 \%$ of farms sampled in the southern US [6]. The use of sustainable, effective nematode parasite control strategies is therefore required $[8,11,12]$.

The anthelmintic value of plants in the diet of grazing livestock is increasingly recognized [13-18]. GIN parasitism is a major cause of sheep and goat mortality in Mexico [8] and other tropical countries [19]. Secondary metabolites of medicinal plants or trees can control various species of nematodes [19-21]. Indoor feeding experiments with young sheep using condensed tannins of willow
Ann Agric Crop Sci - Volume 6 Issue 3 - 2021

ISSN: 2573-3583 | www.austinpublishinggroup.com

Azaizeh et al. () All rights are reserved
Citation: Awwad S, Markovics A, Halahlih F, Yazbak A, Haj-Zaroubi M, Muklada H, et al. Effect of Irrigation Water Source on Secondary Metabolites in Salix acmophylla and Their Potential to Impair Exsheathment of GastroIntestinal Nematodes. Ann Agric Crop Sci. 2021; 6(3): 1079. 
reduced Haemonchus contortus and female Teladorsagia circumcinta worm burdens [22]. Feces incubation also revealed a reduction in L3 larvae for both $H$. contortus and $T$. circumcincta in willow-fed sheep [22]. Grazing sheep on willows may be a sustainable management technique for GIN. This is mainly attributed to the effect of condensed tannins, and may lead to a reduction in use of synthetic anthelmintics [22-24]. We previously demonstrated that an ethanol extract of Salix spp severely impeded development stages of J1-3 of the insect parasitic nematode Heterorhabditis bacter, with 83 to $98 \%$ mortality. The extract also caused 85 to $91 \%$ mortality of nematode eggs [25].

Crops in Mediterranean countries face increasing water stress as groundwater usage increases, annual mean temperatures are greater and annual precipitation decreases, all indicators of increased climate instability [26]. Irrigating with secondary-treated wastewater will greatly enhance its potential economic sustainability of using willow for animal health, since farmers will save costs of both conventional irrigation sources and the need to supply plant fertilizers [7,27].

Our hypothesis was that irrigation of Salix with Treated Wastewater (TWW) compared to Fresh Tap Water (FW) would affect biomass and secondary metabolite production. We evaluated the effects of irrigation source on seasonal variation of growth of different willow ecotypes, as well as their production of secondary metabolites, such as phenols and flavonoids. Subsequently, we investigated the effects of leaf crude extracts on the exsheathment of L3 gastrointestinal nematodes, as well as the minimum concentration with maximum biological activity of subsequent fractions.

\section{Materials and Methods}

\section{Experimental site, soil and irrigation water quality}

The three willow ecotypes Kishon, Golan and Meah Shearim used in the current research were selected from a collection of more than 20 ecotypes collected from different regions in Israel. The selection was based on a genetic analysis, which showed that each of these ecotypes represented one of three well-characterized genotypes of the Salix acmophylla complex [28]. Selection was also based on previous surveys to test Salix biological activity in inhibiting the exsheathment process of parasitic nematodes (unpublished data).

Cuttings of the three genotypes were collected from different regions of Israel and cultivated in a common garden at Ramat Hanadiv Nature Park, located on the southern end of the Carmel mountain ridge, Israel $\left(32^{\circ} 33^{\prime} \mathrm{N}, 34^{\circ} 56^{\prime} \mathrm{E}\right)$. The area is characterized by a Mediterranean climate with hot and dry summers and average annual rainfall of $570 \mathrm{~mm}$. Cuttings from genotypes growing in the common garden were established and grown under ambient temperature in the open field for two years in 50 liter pots (one cutting per pot, with 6 replicates for each genotype) filled with local soil. The soil was sandy silt, consisting of $38 \%$ sand, $26 \%$ silt and $34 \%$ clay. Ramat HaNadiv has a local wastewater facility that recycles wastewater collected from the park's restaurant, toilet facilities services and milking parlor for the resident goatherd. The average wastewater allocation to the study field was 15 cubic meters per day, treated at the secondary level using sedimentation ponds followed by a Rotating Biological Contactor. The plants were irrigated with $500 \mathrm{ml}$ per day per pot up to $3000 \mathrm{ml}$ according to season and soil moisture testing, using two different water types (TWW or FW). Following the guidelines of the Ministry of Health (Israel), the pots irrigated with TWW were separated from those irrigated with FW.

During the study, the irrigation water was sampled monthly from the wastewater treatment plant outlet, and also the tap water using $1 \mathrm{~L}$ sterile glass bottles stored at $4^{\circ} \mathrm{C}$ until analysis. The samples were analyzed in duplicates, according to the Israeli standard methods (17025 IEC/ISO), for the following parameters: Turbidity, Chemical Oxygen Demand (COD) based on (SM-5220D), Total Suspended Solids (TSS) according to D 2540-SM, heavy metals using Inductively Coupled Plasma (ICP) based on SM - 3120 B (Varian 720-ES, Varian medical system Inc., Melbourne, Australia). The $\mathrm{pH}$ was measured in the field using a GLP 22+ pH and Ion-Meter, CRISON. Total Kjeldahl Nitrogen (TKN) was tested, as well as total fecal coliform and total $E$. coli as was described by [29].

\section{Plant material, harvest process and biomass production}

Leaves were collected from each pot of all treatments three times during two consecutive years (2018 and 2019). The first and the second harvests were in July and October 2018 (Harvests 1 and 2), while the third harvest was during June 2019 (Harvest 3). Leaf biomass from each plant was harvested and weighed to determine total fresh weight. Dry Matter (DM) weight of plant leaves was determined by drying at $50^{\circ} \mathrm{C}$ for $48 \mathrm{~h}$ in an air-forced oven.

\section{Quantity and quality of secondary metabolites in willow leaves}

Preparation of plant extracts: In order to evaluate quantity and quality of secondary metabolites in willow leaves, triplicate leaf samples from the different ecotypes collected during the 3 harvests were dried at $50^{\circ} \mathrm{C}$ for $48 \mathrm{~h}$, ground, and stored at room temperature until use. Ten grams of dried leaves, randomly collected from three replicates of each treatment and merged into one composite sample, were incubated with $100 \mathrm{ml}$ of $7: 3$ ethanol:water (v:v) for $24 \mathrm{~h}$. This procedure of extract was used for the bioactive compounds from plants as well as animal food supplement [30]. The mixture was filtered and evaporated under vacuum (Rotorvapor Hie-VAP; Hiedolph, Germany) at $35^{\circ} \mathrm{C}$ to remove the ethanol and water to dryness. The extract yield was calculated using weight of the leaves extract $(\mathrm{g})$ divided by the weight of the leaves before extraction $(\mathrm{g})$ and expressed as g extract per $\mathrm{g}$ DM of plant leaves. The extract was kept at $-20^{\circ} \mathrm{C}$ until analysis.

Phenolic acids and Flavonoid assays: Total phenolic acid content in plant extracts were evaluated and calculated as equivalent of gallic acid or quebracho according to the Folin-Ciocalteu method [31] Zhishen et al. (1999). Salicylic acid content was determined according to previous method [32] and flavonoid content a described in another method [33].

Larval Exsheathment Inhibition Assays (LEIA): The effect of plant extracts from 3 different willow ecotypes irrigated with either FW or TWW were tested on the exsheathment process using the LEIA assay. The L3 developmental stage of the nematode Trichostrongylus colubriformis, a common species in pasture-grazing ruminants in Israel and around the world, was used. Nematodes were obtained from a mono-species infected donor goat and stored in sterile double distilled water at $10^{\circ} \mathrm{C}$ until use. The nematodes were washed 3 times in saline phosphate buffer solution (PBS; $0.01 \mathrm{M}$ phosphate, $0.05 \mathrm{M}$ 
$\mathrm{NaCl}, \mathrm{pH} 7.2$ ), and stored at $10^{\circ} \mathrm{C}$ until analysis. LEIA assay was conducted as previously described [34] using artificial exsheathment solution and a microscope to distinguish between ensheathed (non-exsheathed) and exsheathed nematodes. The percentage of exsheathment was calculated based on an average of 3 replicates per test. Each replicate included approximately $150 \mu \mathrm{l}$ volume of larvae that were incubated in a one ml Eppendorf tube with $30 \mu$ of PBS solution and $150 \mu \mathrm{l}$ of willow ethanol extract at 300-1200 ppm for $3 \mathrm{~h}$ at $37^{\circ} \mathrm{C}$. After incubation, the larvae were washed and centrifuged 3 times in PBS, pH 7.2, then submitted to the artificial process of exsheathment by incubation with an exsheathment solution containing sodium hypochloride $(2 \% \mathrm{w} / \mathrm{v})$ and sodium chloride $(16.5 \% \mathrm{w} / \mathrm{v})$ diluted 1:300 in PBS. The kinetics of exsheathment were determined by removing a $15 \mu$ l sample (containing 20-30 L3 nematodes) from the Eppendorf tube and counting the number of exsheathed and ensheathed individuals under a microscopic $(\times 400)$ at time intervals of $0,15,30,45$, and $60 \mathrm{~min}$ after incubation with the exsheathment solution. Counts were averaged within each time point. Three replicates were run for each plant extract sample (300$1200 \mathrm{ppm}$ ) and compared to a negative control (L3 in water and PBS) which was run in parallel during the assay. Based on the Effective Concentration (EC) of the crude ethanol extract from previous experiments (data not shown) which caused $\geq 80 \%$ exsheathment inhibition, we decided to use $1200 \mathrm{ppm}$ for all these experiments for comparison.

\section{HPLC analysis of phenolic compounds}

HPLC analysis was performed to characterize the ethanol willow extract, which showed maximal nematode exsheathment activity. The analysis was based on the spectral profiles of the compounds using the PDA HPLC detector, and compared to compounds with a known spectral profile [30]. HPLC analysis was also performed to compare the composition of the phenolic compounds between the different willow ecotypes and the concentration of the various components in an active extract and an inactive extract. For hydrolysis, 100mg of each dried plant extract was dissolved in $20 \mathrm{ml}$ acetonitrile with methanol (1:1) (v:v) for sample preparation. The presence of phenolic acids and flavonoids was studied using reversed-phase HPLC analysis with binary gradient elution on a Thermo Scientific Finnigan Surveyor system equipped with a PDA Plus Detector (220-360 nm) (Thermo Fisher Scientific Inc., Waltham, MA, USA). The chromatographic separation was performed on a Sonoma C18 (2) $100 \mathrm{~A}^{\circ}$ column $(25 \mathrm{~cm} \times 4.6 \mathrm{~mm})$ ES Industries, USA. The mobile phase included two solvents, water (A) and acetonitrile with methanol (1:1) (v:v); (B) with acetic acid $(0.1 \%)$, for a total running time of $80 \mathrm{~min}$. The elution conditions were: 0-5 $\mathrm{min}, 5 \% \mathrm{~B}$; 5-10 $\mathrm{min}, 5-10 \% \mathrm{~B}$; 10-55 min, 10$50 \%$ B; 55-65 min, 50-70 \% B; 65-70 min, 70-90 \% B; 70-80 min, 90-5 $\% \mathrm{~B}$. The flow rate was $1 \mathrm{ml} / \mathrm{min}$ and the injection volume was $15 \mu \mathrm{l}$.

\section{Fractionation process to determine the minimum} concentration with maximum biological activity

For the fractionation process, we selected the willow plant extract with the highest amount of active compounds relative to the other ecotypes, at each harvest, and with the highest exsheathment inhibition using the LEIA test. Samples of $40 \mathrm{~g}$ of fine powdered willow leaves were extracted by adding $200 \mathrm{ml}$ of solvents with increasing polarity level in the following order: hexane, hexane and ethyl acetate (1:1) (v:v), ethyl acetate and finally $80 \%$ methanol with $20 \%$ water.
Fractions were evaporated using a rotating vacuum evaporator at $45^{\circ} \mathrm{C}$ (Rotorvapor Hie-VAP; Hiedolph, Germany) and were stored at $-20^{\circ} \mathrm{C}$ until analysis. The LEIA assay was performed at $300-1200 \mathrm{ppm}$ for each fraction as previously described. The fraction that resulted in the greatest inhibition of exsheathment when tested on the L3 larvae was examined to determine the minimum concentration with maximum biological activity.

\section{Statistical analysis}

The factorial design of the experiment included irrigation with TWW or FW of 3 replicates each of the three willow ecotypes from each of three different harvests. Statistical analysis was carried out with PRISM 8 statistical software. One-way ANOVA tests were used to test significance for all the data in the study $(\mathrm{p}<0.05)$.

\section{Results}

\section{Willow biomass and water irrigation}

The qualities of the TWW used during the two years were similar, the average of 3 replicates from 2019 was as follow: $\mathrm{pH}=7.2+0.1$, turbidity $=7.3+1.8 \mathrm{NTU}, \mathrm{COD}=62.1+15.7 \mathrm{mg} / \mathrm{L}$, TSS $=10.0+1.3$ $\mathrm{mg} / \mathrm{L}, \mathrm{TKN}=8.9+1.1 \mathrm{mg} / \mathrm{L}$. The fresh weight of leaves of the three willow ecotypes ranged from 103 to $473 \mathrm{~g}$ (Figure 1). There was a significant effect of water quality (FW compared with TWW) and willow ecotype on the weight of leaves collected during 2018 and 2019 $(\mathrm{p}<0.05$, Figure 1). Using TWW irrigation resulted in most cases in the doubling of biomass production compared to FW. The maximum fresh leaves weight was obtained for Kishon ecotype harvested in 2019 and irrigated with TWW.

\section{Secondary metabolites in willow biomass}

Similar contents of salicylic acid were found in the dried leaves of willow ecotypes irrigated with FW (between 8-14\% (DW:DW), and plants irrigated with TWW $(7-13 \% \mathrm{w} / \mathrm{w})$ Total phenolic content $(\mathrm{mg})$ equivalent to gallic acid $(\mathrm{mg})$ or quebracho $(\mathrm{mg})$ in plant extract ranged between $9-28 \%$ and $18-53 \%$, respectively (Figure 2). No significant differences in phenolic content were found between irrigation regimes for Kishon and Meah Shearim ecotypes during the three harvests. On the other hand, phenolic content in the

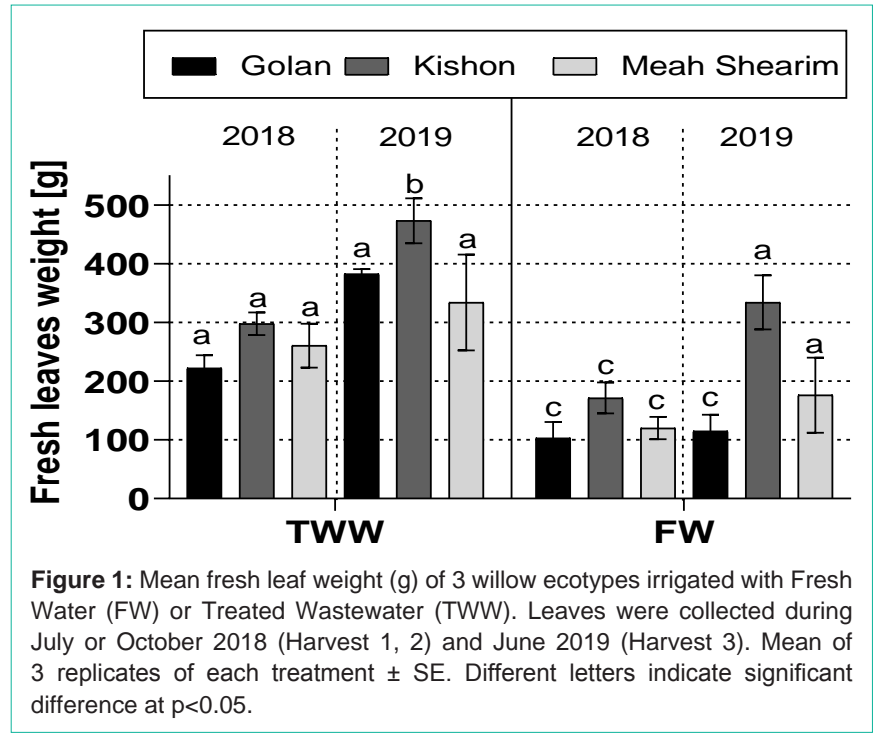




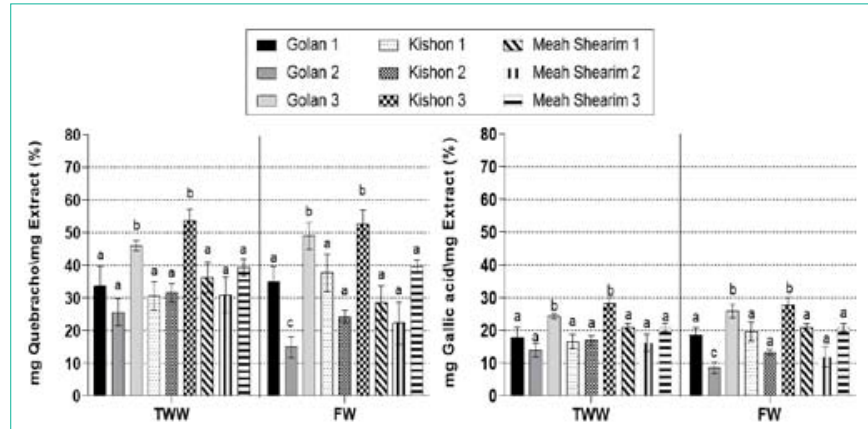

Figure 2: Phenol content as mg quebracho (left) or mg gallic acid (right) or as per mg plant crude extract of 3 willow ecotypes irrigated with Fresh Tap Water (FW) compared with Treated Wastewater (TWW) collected during July, or October 2018 (Harvest 1,2) and June 2019 (Harvest 3). Mean of 3 replicates of each treatment \pm SE. Numbers appearing with the names of the willow ecotypes indicate the harvest season. Different letters indicate significant difference at $p>0.05$.

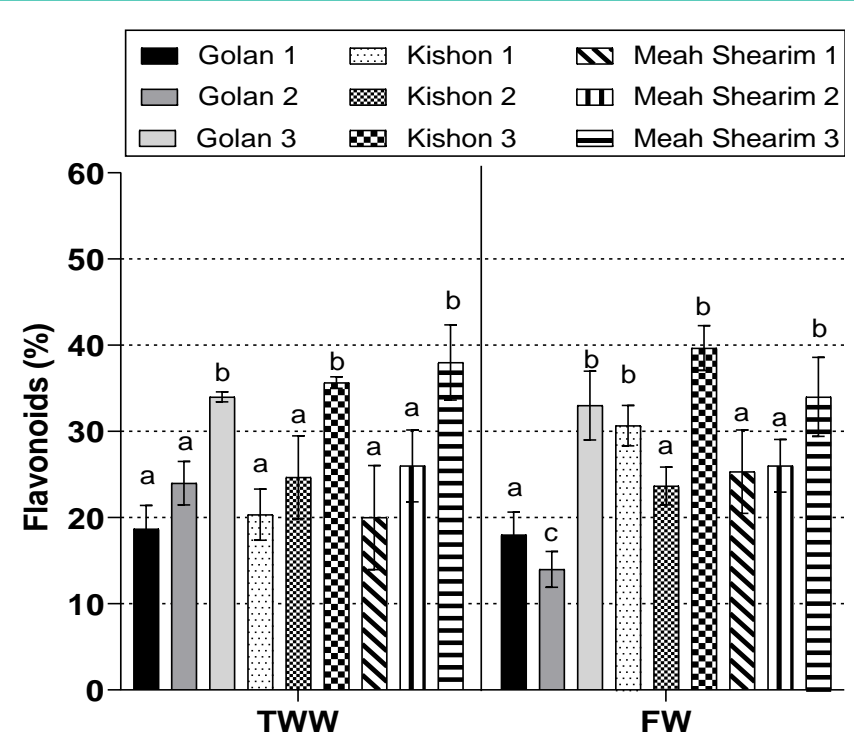

Figure 3: Flavonoid content (\%) (DW: DW) of 3 willow ecotypes irrigated with Fresh Water (FW) or Treated Wastewater (TWW) collected in July, October 2018 (Harvest 1, 2) and June 2019 (Harvest 3). Mean of 3 replicates of each treatment \pm SE. Numbers appear with the names of the willow ecotypes indicate the season of the plant collection. Different letters indicate significant difference at $\mathrm{p}>0.05$

Golan ecotype from harvest 2 was significantly higher when trees were irrigated with TWW. Willow ecotype and harvest season had a significant effect on the phenolic content of willow extracts (Figure 2). Total phenol contents in harvest 3 (June 2019) for the Kishon ecotype were higher than the content in the other ecotypes of harvest 1 and 2, regardless of the irrigation source (Figure 2).

Flavonoid content of the ethanolic extracts of the different willow ecotypes ranged between 14-40 \% (DW:DW) (Figure 3). There was no significant effect of water source on the flavonoid content for all harvests. However, irrigation water source had a significant effect on flavonoid in the Golan ecotype collected during harvest 2 and the Kishon ecotype collected during harvest 1 . Flavonoid content of the three ecotypes was highest at harvest 3 (June 2019) regardless of the irrigation source, with Kishon ecotype having the highest concentration over all (Figure 3).

\section{Larval Exsheathment Inhibition Assays (LEIA)}

We previously found that a maximum exsheathment inhibition of $\geq 80 \%$ was obtained using ethanol extract concentrations of $1200 \mathrm{ppm}$ of different willow ecotypes (Azaizeh, unpublished); therefore, we tested our current extracts using 1200ppm. Crude ethanol extracts from all three willow ecotypes collected during harvest 1, 2 and 3 resulted in exsheathment of $0.5-14,4-35 \%$ and $1-8 \%$, respectively (Figure 4 ). There was no effect of irrigation source on the exsheathment process (Figure 4), but exsheathment was affected differentially by willow ecotype at harvest 2. Maximum exsheathment inhibition (97-99 \%) was obtained with the Kishon ecotype, irrespective of the irrigation source (Figure 4). Harvest 3 resulted in more than 90\% exsheathment inhibition for all ecotypes regardless of the irrigation source.

\section{HPLC analysis of phenolic compounds and extracts fractionation}

Extract of Kishon irrigated with FW and collected during harvest 3 was the strongest inhibitor of exsheathment. The extract contained 14 known phenolic compounds including salicin and its derivatives, caffeic acid, catechin, chlorogenic acid, a p-coumaric acid derivative, ferulic acid, salicylic acid, myrcetin, querctin and its derivatives, and rutin.

As Kishon ecotype showed the highest nematode exsheathment inhibition irrespective of the irrigation water type, therefore, it was selected for the fractionation characterization tests where 4 different fractions were obtained. The quality of the different fractions on exsheathment inhibition was also evaluated using 1200ppm. The results show that ethyl acetate fraction had the maximum activity on nematode exsheathment inhibition (100\% inhibition) relative to the other fractions and even better than the original ethanol crude fraction (Figure 5). The ethyl acetate: hexane and hexane fraction also showed high inhibition (90-97\%) of the exsheathment (Figure 5).

\section{LEIA test of the ethyl acetate fractions}

To determine the minimum concentration of ethyl acetate fraction with maximal nematode exsheathment inhibition activity, we tested the effect of different concentrations of ethyl acetate fraction on the exsheathment process. The concentrations of ethyl acetate fraction that had the highest inhibition on exsheathment were: 900 and $1200 \mathrm{ppm}$ (Figure 6). Therefore, the minimum concentration with maximum exsheathment inhibition (almost 100\%) was obtained at $900 \mathrm{ppm}$.

Chemical fractionation of the ethyl acetate fraction of the Kishon ecotype resulted in 5 different sub-fractions a, b, c, d, e, where only sub-fraction c caused more than $90 \%$ exsheathment inhibition when tested on the L3 larval stage (Figure 7). The other sub-fractions resulted in almost no inhibition. The original ethyl acetate fraction was more active than any of the individual sub-fractions (Figure 7).

\section{Discussion}

Intestinal GIN parasites in livestock have been developing increasing resistance globally to synthetic anthelmintic compounds, costing billions of dollars annually in loss of revenue worldwide $[6,10,20]$. Until recently, researchers have overlooked the possibilities inherent in plant-derived anthelmintic compounds, including 


\section{Golan $\square$ Kishon $\square$ Meah Shearim}
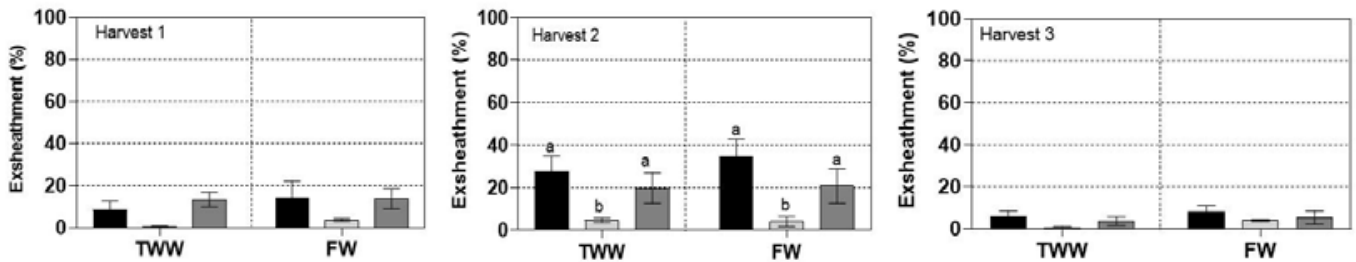

Figure 4: Effect of ethanol extracts of 3 different willow ecotypes collected during 2018 (July and October) and June 2019, termed "harvest 1", "harvest 2" and "harvest 3 " respectively at $1200 p p m$ on the exsheathment of parasitic nematodes process during 60 min incubation compared to control. Mean of 3 replicates of each treatment \pm SE.

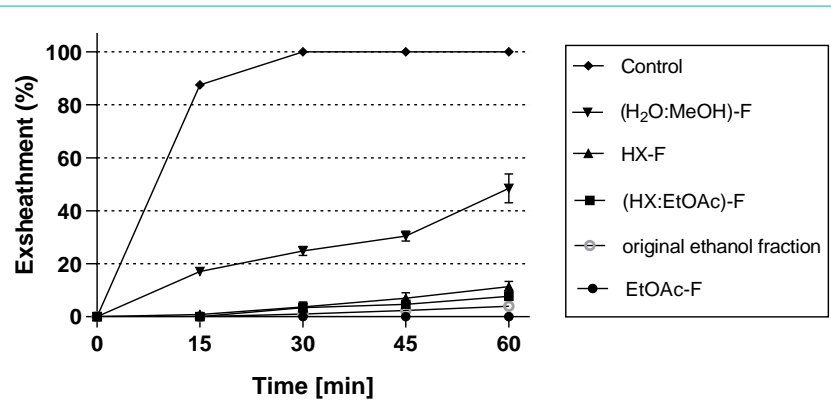

Figure 5: Effect of different fractions of the ethanol fraction of the Kishon willow ecotype at 1200ppm on the exsheathment process during 60min incubation compared to the control and the original ethanol crude fraction. Mean of 3 replicates \pm SE. Water: methanol fraction $\left(\mathrm{H}_{2} \mathrm{O}: \mathrm{MeOH}-\mathrm{F}\right)$; Hexane Fraction (HX-F); hexane: ethyl acetate fraction (HX: EtOAc-F); ethyl acetate fraction (EtOAc-F).

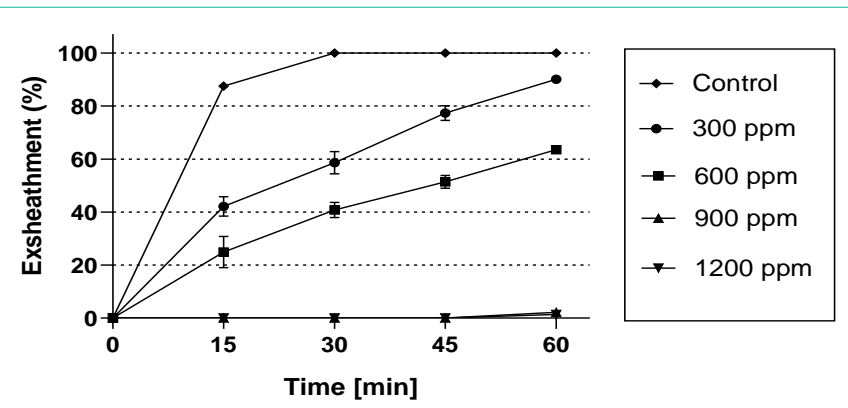

Figure 6: Effect of different concentrations (300, 600, 900, and 1200 ppm) of ethyl acetate fraction from Kishon ecotype compared to control on the exsheathment process during $60 \mathrm{~min}$ of incubation. Mean of 3 replicates $\pm \mathrm{SE}$.

feeding livestock with medicinal plants [20]. Secondary metabolites found in plants could be of great importance in the agricultural pharmaceutical industry. Willow foliage is a palatable and effective dietary supplement for animal feed, as well as an anthelmintic for parasitic GIN nematodes [7]. The irrigation of willow plants with TWW in most cases doubled the fresh biomass yield compared to FW due to high nitrogen and other fertilizer-like compounds in the TWW compared with the FW (Figure 1). It is well known that urban wastewater can be an important source of nutrients and water for plant growth especially willow. Willow plants irrigated with secondarily treated wastewater and consumed as green fodder can be a viable solution for using this otherwise-discarded resource to increase plant biomass [7]. Only negligible amounts (less than the legal level of contamination) of heavy metals were accumulated in

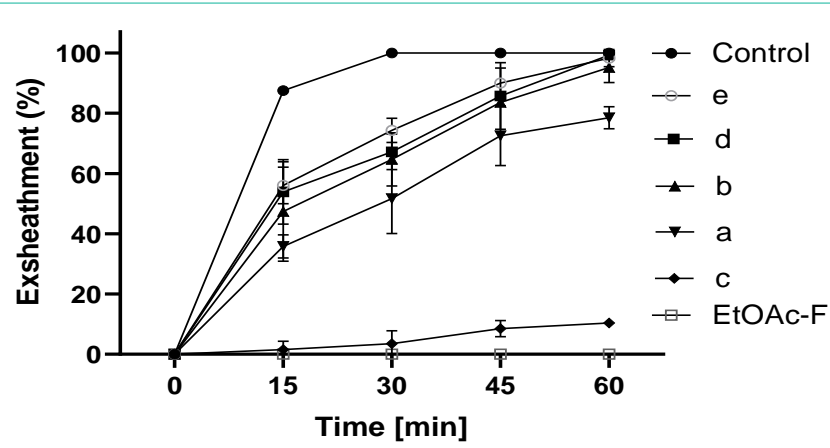

Figure 7: Effect of different fractions obtained from the ethyl acetate fraction of Kishon willow ecotype using TLC Prep at $1200 \mathrm{ppm}$ compared to control and to the original EtOAc-F on the exsheathment process during $60 \mathrm{~min}$ incubation. Mean of 3 replicates \pm SE.

willow plants irrigated by TWW [7] similar to our results (data not showed), so there is no health risk for animal feeding on the willow foliage.

Various parameters could affect secondary metabolites extracted from different plants, including willow $[29,35,36]$. We found that the amount of phenols and flavonoids in willow ecotypes is primarily dependent on the cultivated ecotype, but not on water quality (Figure 2 and 3). Similarly, different willow cultivars cultivated in Quebec, Canada, also varied in concentrations of phenolic compounds such as hydroxycinnamic acid and derivatives, benzoic acid derivatives, flavonols and condensed tannins [37].

The concentration of phenolic compounds and flavonoids in the leaves of the different ecotypes depended on the harvest period. The total phenols of Kishon leaves from harvest 3 were higher than those in other ecotypes of harvest 1 and 2, regardless of the type of irrigation water. The phenolic glycoside profiles of Salix bark vary among species and between the harvesting seasons. The major salicylate of $S$. daphnoides and S. purpurea clones was salicortin, whereas the main compound of S. pentandra was 2'-O-acetylsalicortin [38]. The secondary metabolite content of willow bark clones decreased during the vegetative season where the optimum yield of phenolic glycosides of the species, and the time of harvest during the season have to be taken into consideration [38] which support our results that the harvest period affects the phenolic content in addition to the tested ecotype. The timing of willow harvest during the growing season affects the quality and quantity of the harvested biomass, and has implications for the quantity of nutrients removed from the soil 
and the potential need for replacement by fertilization [2]. Therefore, using TWW rich with nutrients such as nitrogen and phosphorus has great potential for the production of high biomass from irrigated willows and the harvest period affects total secondary metabolites.

Infection with GIN nematodes remains a serious animal health problem all over the world, with significant effects on animal health and reproduction $[6,9]$. In order to avoid the development of resistance to chemical compounds that control GINs, alternatives such as extracts with natural compounds or the consumption of whole plants such as willows, prevent both undesirable side effects and the development of resistance to synthetic compounds [11,12]. Consumption of willow plants caused a reduction in the number of parasitic nematodes in affected ruminants $[22,25,39]$. Willow foliage contains relatively high amounts of secondary metabolites with great anthelmintic potential, depending on the willow ecotype, for inhibition of nematode exsheathment. In our work we cultivated 3 ecotypes where each one is a representative of the three genotypes that found in a previous work [28]. A 1200ppm solution of phenolic crude ethanol extract of the Kishon ecotype resulted in more than $90 \%$ exsheathment inhibition, regardless of harvest time or source of irrigation water (Figure 5). An ethanol extract of S. alba (acmophylla) had a highly toxic effect on the development of the parasitic nematode $H$. bacter, and even caused mortality, in addition to toxic effects on egg survival [25]. We suggest that the phenolic compounds contained in high levels in willow plants could be considered as an alternative treatment and natural drug source, which could be an environmentally friendly solution for the control of parasitic GIN nematodes in animals.

Irrigation water source had no effect on the secondary metabolites, and willow plants did not undergo stress from irrigation with TWW. Choosing the right willow ecotype and harvest season are also important factors to obtain a high production level of biomass and secondary metabolites. We found a difference in the chemical profile of glycoside phenols among the ecotypes, as well as differences in. biomass and secondary metabolite production. This was clear in the concentration of phenols and flavonoids accumulated by the leaves, and affected the biological activity that inhibits the nematode exsheathment process (Figure 4 and 5). The optimum season for harvest for maximum yield and activity was the beginning of summer, compared to the other seasons tested (mid-summer and fall).

Active compounds isolated from willows and other plants are a promising alternative source to synthetic drugs [10-12,17,18,25]. Exsheathment inhibition is associated mainly with variation for polyphenols in the forage (Azaizeh et al., unpublished). In the current study, we were able to isolate and identify 14 phenolic acids and flavonoids from willow leaves, which included compounds known for their effect on GIN development. Previous studies showed that galloyl derivatives of catechin prevent exsheathment of $H$. contortus and $T$. colubriformis larvae [40]. Catechin and other galloyl derivatives were detected in our phenolic extract of willow.

Salicin, the most common phenolic glucoside found in willows, can be converted into the nonsteroidal anti-inflammatory drug, acetylsalicylic acid (commercially known as aspirin) [41]. In addition, sodium salicylate of willow given in early lactation has beneficial effects throughout the whole lactation period of mature dairy cows [39]. Fractionation of the Kishon ethanol crude extract resulted in a sub- fraction of ethyl acetate with maximum anthelmintic activity (100\% inhibition of nematode exsheathment) at a minimum concentration of 900 ppm (Figure 5 and 6). This fraction was even better than the original ethanol crude fraction. Subsequent separations of the Kishon willow ethyl acetate fraction resulted in 5 sub-fractions, but the most active fraction (c), was much less active than the overall ethyl acetate fraction: a $90 \%$ inhibition of larval exsheathment was achieved only at $1200 \mathrm{ppm}$ (Figure 7). Further fractionation of the crude extract and isolation of a single compound will likely cause a further reduction in larval exsheathment inhibition, since there seems to be a synergistic anthelmintic effect of a mixture of natural compounds found in willow leaves.

Willow trees can resist environmental stress, have high growth potential, and are considered a suitable crop for a wide range of applications in different geographic regions [1,2,42]. Further verification by mid or long-term research is required, but our results clearly demonstrate that willow trees irrigated with TWW are a renewable resource that could produce appreciable amounts of biomass to be used as fodder for livestock husbandry as well as an inexpensive natural source of bioactive compounds for controlling GIN.

\section{Conclusion}

Irrigation of Salix with TWW resulted in the doubling of biomass production. The chemical profiles of the phenolic compounds depend on the willow ecotype. Kishon ecotype extracts consistently inhibited L3 larval exsheathment by more than $90 \%$. Ethyl acetate fraction in addition to ethanol crude extract obtained from Kishon ecotype was with high activity in the inhibition of GIN exsheathment. While it is clear that willow ecotype selection is an important criterion for biomass production, a large-scale planting is still required in order to verify our conclusions.

\section{Acknowledgement}

This work was partially supported by MERC (Middle East Regional Cooperation - U.S. Agency for International Development), grant M33-018. Great thanks to Prof. Georg von SamsonHimmelstjerna, Freie University Berlin, Institute for Parasitology and Tropical Veterinary Medicine, Berlin, Germany for providing us with the mono-species nematode. Thanks to Dr. Sary Asli, R\&D Galilee Society for his help in the statistical analysis of the data.

\section{References}

1. Kuzovkina YA, Knee M, Quigley MF. Effects of soil compaction and flooding on the growth of 12 willow (Salix L.) species. J Environm Hort. 3004; 22: 155-160.

2. Larsen SU, Lærke PE, Jørgensen U. Harvest of green willow biomass for feed - effects of harvest time and frequency on yield, nutrient concentration, silage quality and regrowth. Acta Agri Scand. 2020.

3. Saller R, Melzer J, Felder M. Pain relief with a proprietary extract of Willow bark in rheumatology. An Open Trial Schweiz Zschr GanzheitsMedizin. 2008; 20: 156-162.

4. Boeckler GA, Gershenzon J, Unsicker SB. Phenolic glycosides of the Salicaceae and their role as anti-herbivore defenses. Phytochem. 2011; 72: 1497-1509.

5. Landau S, Azaizeh H, Muklada H, Glasser E, Ungar D, et al. Anthelmintic activity of Pistacia lentiscus foliage in two Middle Eastern breeds of goats differing in their propensity to consume tannin-rich browse. Vet Parasitol. 


\section{0; $173: 280-286$.}

6. Howell SB, Burke JM, Miller JE, Terrill TH, Valencia E, et al. Prevalence of anthelmintic resistance on sheep and goat farms in the southeastern United States. J Am Vet Med Assoc. 2008; 233: 1913-1919.

7. Muklada H, Klein J, Glasser T, Dvash L, Azaizeh H, Davidovich-Rikanati $\mathrm{R}$, et al. Initial evaluation of willow (Salix acmophylla) irrigated with treated wastewater as a fodder crop for dairy goats. Small Rum Res. 2018; 163 : 76-83.

8. Canul-Ku HL, Rodríguez-Vivas RI, Torres-Acosta JF, Aguilar-Caballero AJ, Pérez-Cogollo LC, et al. Prevalence of cattle herds with ivermectin resistan nematodes in the hot sub-humid tropics of Mexico. Vet Parasitol. 2012; 183 292-298.

9. Jackson F, Coop RL. The development of anthelmintic resistance in sheep nematodes. Parasitol. 2000; 120: 95-107.

10. Kaplan RM. Drug resistance in nematodes of veterinary importance: a status report. Trends Parasitol. 2004; 20: 477-481.

11. Waller PJ. From discovery to development: current industry perspectives for the development of novel methods of helminth control in livestock. Ve Parasitol. 2006a; 39: 1-14.

12. Waller PJ. Sustainable nematode parasite control strategies for ruminant livestock by grazing management and biological control. Anim. Feed Sci Technol. 2006b; 126: 277-289.

13. Athanasiadou S, Kyriazakis I. Plant secondary metabolites: antiparasitic effects and their role in ruminant production systems. Proc Nutr Soc. 2004 63: 631-639.

14. Molan AL, Meagher LP, Spencer PA, Sivakumaran S. Effects of flavan-3-ols on in vitro egg hatching, larval development and viability of infective larvae of Trichostrongylus colubriformis. Int Parasitol. 2003; 33: 1691-1698.

15. Athanasiadou S, Kyriazakis I, Jackson F, Coop RL. Direct anthelmintic effects of condensed tannins towards different gastrointestinal nematodes of sheep: in vitro and in vivo studies. Vet Parasitol. 2001; 99: 205-219.

16. Athanasiadou S, Githiori J, Kyriazakis I. Medicinal plants for helminth parasite control: facts and fiction Anim. 2007; 1: 1392-1400

17. Hoste H, Jackson F, Athanasiadou S, Thamsborg SM, Hoskin SO. The effects of tannin-rich plants on parasitic nematodes in ruminants. Trends Parasitol. 2006; 22: 253-261.

18. Hoste H, Sotiraki S, Landau SY, Jackson FJ, Beveridge I. Goat-Nematode interactions: think differently! Trends Parasitol. 2010; 26: 376-381.

19. Carvalho CO, Chagas ACS, Cotinguiba F, Furlan M, Brito LG, et al. The anthelmintic effect of plant extracts on Haemonchus contortus and Strongyloides venezuelensis. Vet Parasitol. 2012; 183: 260-268.

20. French KE. Plant-Based Solutions to Global Livestock Anthelmintic Resistance. Ethnobiolo Letters. 2018; 9.

21. Lavola A, Maukonen M, Julkunen-Tiitto R. Variability in the composition of phenolic compounds in winter-dormant Salix pyrolifolia in relation to plant part and age. Phytochem. 2018; 153: 102-110.

22. Mupeyo B, Barry TN, Pomroy WE, Ramírez-Restrepo CA, López-Villalobos et al. Effects of feeding willow (Salix spp.) upon death of established parasites and parasite fecundity. Anim Feed Sci Technol. 2011; 164: 8-20.

23. Diaz Lira CM, Barry TN, Pomroy WE, McWilliam EL, Lopez-Villalobos N. Willow (Salix spp.) fodder blocks for growth and sustainable management of internal parasites in grazing lambs. Anim Feed Sci Technol. 2008; 141 61-81.

24. Ramírez-Restrepo CA, Pernthaner A, Barry TN, López-Villalobos N, Shaw $\mathrm{RJ}$, et al. Characterization of immune responses against gastrointestinal nematodes in weaned lambs grazing willow fodder blocks. Anim. Feed Sc Technol. 2010; 155: 99-110.

25. Santhi VS, Salame L, Dvash L, Muklada H, Azaizeh H, et al. Ethanolic extracts of Inula viscosa, Salix alba and Quercus calliprinos, negatively affect the development of the entomopathogenic nematode, Heterorhabditis bacteriophora - a model to compare GINs developmental effect. J Invert Pathol. 2017; 145: 39-44.

26. Milano M, Ruelland D, Fernandez S, Dezetter A, Fabre J, et al. Facing climatic and anthropogenic changes in the Mediterranean basin: What will be the medium-term impact on water stress. Comptes Rendus Geosci. 2012; 344: 432-440.

27. Rosenqvist $H$, Dawson $M$. Economics of using wastewater irrigation of willow in Northern Ireland. Biomass and Bioen. 2005; 29: 83-92.

28. Muklada $H$, Voet $H$, Deutch $T$, Zachut M, Kra G, et al. The effect of willow fodder feeding on immune cell populations in the blood and milk of latelactating dairy goats. Anim. 2020; 14: 122511-122522.

29. Azaizeh $H$. Effects of mineral nutrients on physiological and biochemical processes related to secondary metabolites production in medicinal herbs. Chapter in: Medicinal and Aromatic Plant Science and Biotechnology. 2012; 6: $105-110$

30. Azaizeh H, Halahleh F, Abbas N, Markovics A, Muklada H, et al. Polyphenols from Pistacia lentiscus and Phillyrea latifolia impair the exsheathment of gastro-intestinal nematode larvae. Vet Parasitol. 2013; 191: 44-50.

31. Zhishen J, Mengcheng T, Jianming W. Determination of flavonoid contents in mulberry and their scavenging effects on superoxide radicals. Food Chem. 1999; 64: 555-559.

32. Warrier RR, Paul M, Vineetha MV. Estimation of salicylic acid in Eucalyptus leaves using spectrophotometric methods. Gen. and Plant Physiol. 2013; 3: 90-97.

33. Zhang G, Li He L, Hu M. Optimized ultrasonic-assisted extraction of flavonoids from Prunella vulgaris $L$. and evaluation of antioxidant activities in vitro. Innov Food Sci and Emerg Technol. 2011; 12: 18-25.

34. Bahuaud D, Martinez-Ortiz de Montellano C, Chaveau, S, Prevot F, TorresAcosta $F$, et al. Effects of four tanniferous plant extracts on the in vitro exsheathment of third stage larvae of parasitic nematodes. Parasitol. 2006; 132: 545-554.

35. Brossa R, Casals I, Pintó-Marijuan M, Fleck I. Leaf flavonoid content in Quercus ilex L. resprouts and its seasonal variation Trees. 2010; 23: 401408.

36. Noleto-Dias C, Yanqi Wu Y, Bellisai A, Macalpine $\mathrm{W}$, Beale $\mathrm{MH}$, et al. Phenylalkanoid glycosides (Non-Salicinoids) from wood chips of Salix triandra $x$ dasyclados hybrid willow. Molecules. 2019; 24: 1152.

37. Brereton NJB, Berthod N, Lafleur B, Pedneault K, Pitre FE, et al. Extractable phenolic yield variation in five cultivars of mature short rotation coppice willow from four plantations in Quebec. Ind Crops Prod. 97, 525-535.

38. Förster N, Ulrichs C, Zander M, Kätzel R, Mewis I. Influence of the season on the salicylate and phenolic glycoside contents in the bark of Salix daphnoides, Salix pentandra, and Salix purpurea. J Appl. Bot. Food Qual. 2008; 82: 99102.

39. Farney JK, Mamedova LK, Coetzee JF, Minton JE, Hollis LC, et al. Sodium salicylate treatment in early lactation increases whole-lactation milk and milk fat yield in mature dairy cows. J Dairy Sci. 2013; 96: 7709-7718.

40. Brunet S, Hoste $\mathrm{H}$. Monomers of condensed tannins affect the larval exsheathment of parasitic nematodes of ruminants. J Agric Food Chem. 2006; 54: 7481-7487.

41. Kammerer B, Kahlich R, Biegert C, Gleiter CH, Heide L. HPLC-MS/MS analysis of willow bark extracts contained in pharmaceutical preparations. Phytochem Anal. 2005; 16: 470-478.

42. Moore KM, Barry TN, Cameron PN, Lopez-Villalobos N, Cameron DJ. Willow (Salix spp.) as a supplement for grazing cattle under drought conditions. Anim Feed Sci Technol. 2003; 104: 1-11. 